EESTI NSV TEADUSTE AKADEEMIA TOIMETISED. 31. KOIDE GEOLOOGIA. 1982, NR. 2

ИЗВЕСТИЯ АКАДЕМИИ НАУК ЭСТОНСКОИ ССР. ТОМ 31 ГЕОЛОГИЯ. 1982, № 2

удК $551.312: 550.42(474.2)$

Лейли СААРСЕ, Я. КЯРСОН

\title{
ИСОБЕННОСТИ ОСАДКОНАКОПЛЕНИЯ В ОЗЕРАХ ЭЛИСТВЕРЕ, ПРОССА И ПИККЪЯРВ
}

На Саадъярвском друмлинном поле насчитывается 13 озер, занимающих продолговатые междрумлинные впадины и ориентированные с северо-запада на юго-восток, в соответствии с направлением движения ледника. Более ранними исследованиями (Мянниль, 1967; Пиррус, 1969; Veber, 1964; Mäemets, 1977; Pirrus, Rõuk, 1979 и др.) выявлены морфометрия, гидробиология, гидрохимия, стратиграфия и осадки озер, последние в основном в заросшей части впадин. Отложения акватории, как наиболее труднодоступные, до последнего времени оставались мало изученными.

Летом 1979/80 г. на озерах Элиствере, Просса и Пиккъярв, расположение которых показано на рис. 1, с катамарана авторами проведено бурение. Выявлены морфология первичной озерной впадины, состав и характер донных отложений и особенности осадконакопления в названных озерах. Учитывая, что палинологическая характеристика, стратипрафическое расчленение и особенности развития растительности в Саадъярвском друмлинном поле весьма исчерпывающе освещены Р. Пиррусом (Пиррус, 1969; Pirrus, Rõuk, 1979), в данной статье они рассматриваются бегло.

Изученные озера мелководные, илистые, слабопроточные, с искусственно опущенным уровнем воды, средней минерализацией гидрокарбонатно-кальциевой воды (Eesti järved, 1968). Формирование озерных впадин в Саадъярвском друмлинном поле сложно и окончательно

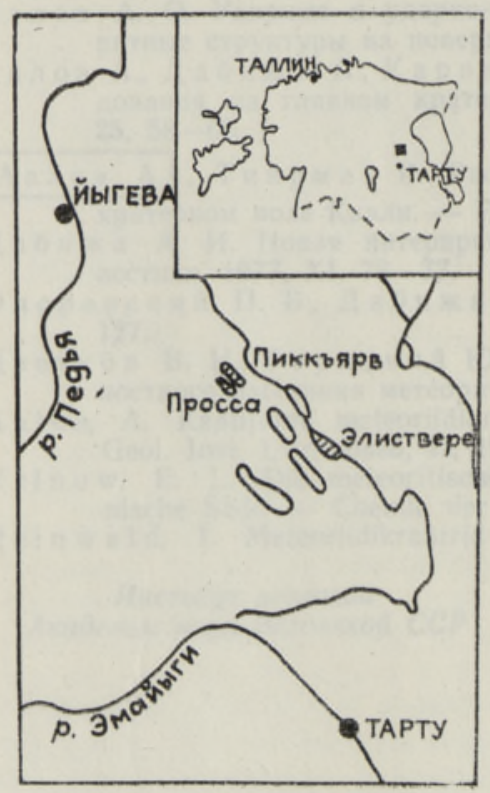
не выявлено. Предполагается, что они образовались в результате экзарационноаккумулятивной деятельности ледника (Орвику, 1961; Каяк, 1965; Рыук, 1974) в условиях относительно быстрых дивергентных струй активного льда. В процессе прогрессирующего вымирания ледника образовались поля пассивного и мертвого льда, сопровождающиеся сильными флювиогляциальными потоками. Вероятно, тогда в ходе кратковременной подвижки ледника (Раукас и др., 1971) и образовались своеобразные попребенные «трогообразные плечи», фрагменты которых можно найти на бортах впадин изученных озер (рис. 2).

Дно озерных впадин расчленено мезоформами, прежде всего моренными буграми и долинообразными понижениями

Рис. 1. Схема расположения изученных озер. 


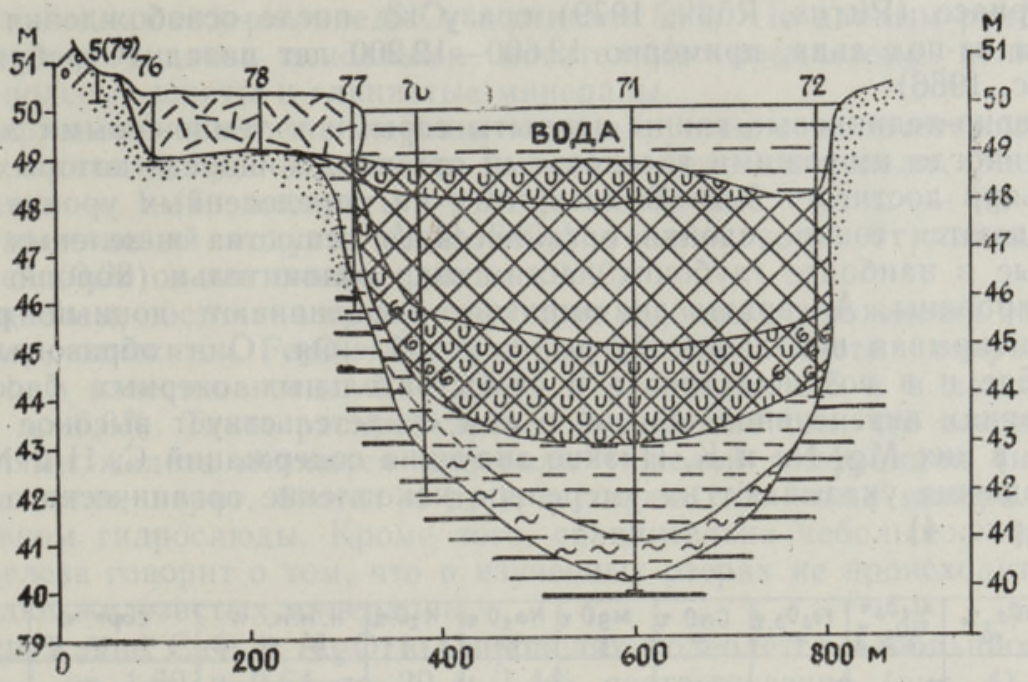

Рис. 2. «Трогообразное плечо» во впадине 0з. Элиствере. Условные обозначения см. на рис. 3.

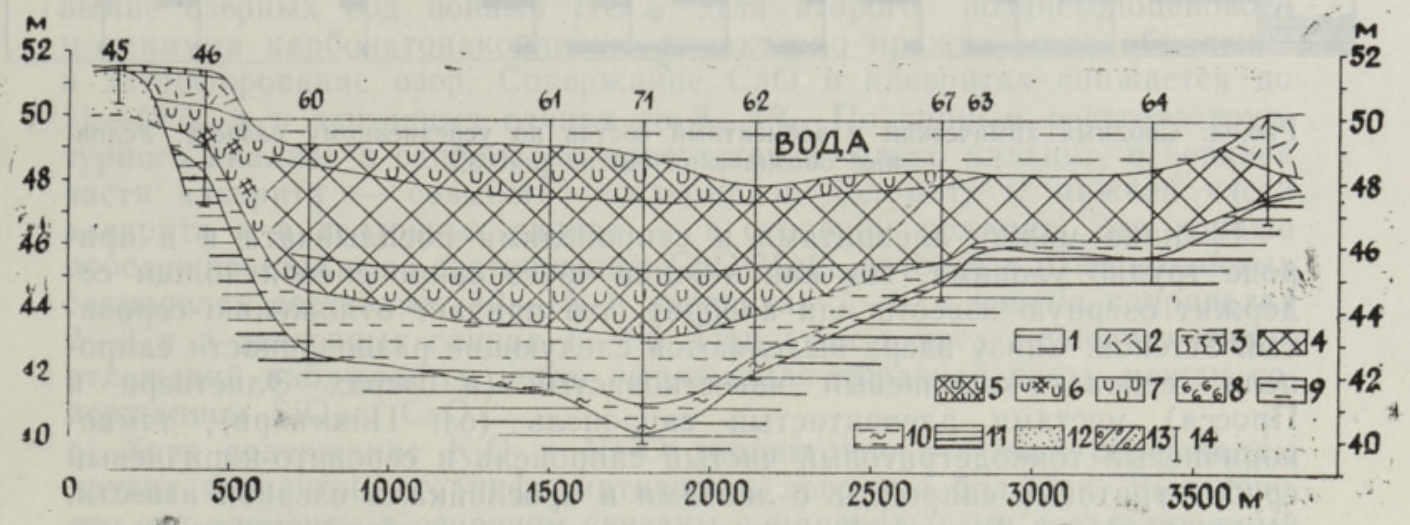

Рис. 3. Продольный профиль оз. Элиствере. 1 - вода, 2 - торф, 3 - почва, 4 сапропель, 5 - известковистый сапропель, 6 - сапропелевая озерная известь, 7 - озерная известь, 8 - фрагменты субфоссильных моллюсков, 9 - алеврит, 10 алеврит с органическим веществом, 11 - ленточная глина, 12 - песок, 13 - морена, 14 - буровые скважины.

(рис. 3). Первые вытаивали из погребенных ледяных глыб, вторые образовались талыми ледниковыми водами. Этими процессами в основном закончилось формирование первичных озерных ванн.

В ходе образования местных приледниковых водоемов во впадинах изученных озер начали формироваться бежевые ленточные тлины. Мощность ленточных глин в заросшей части в среднем $1,5-2,5$ м и в наиболее глубоких частях современных озер более 3 м. Отдельные ленты весьма крупные $(3-4$ cм) и позволяют предполагать, что вся толща ленточных глин образовалась в течение 50-100 лет. Хотя ленточные глины имеют тенденцию сглаживать неровности первичного донного рельефа, их мощность все же недостаточна для полного выравнивания (рис. 3). Поэтому поверхность ленточных глин неровная и прослеживает в общих чертах первичный рельеф озерных впадин. По данным спорово-пыльцевого анализа ленточные глины накапливались в сред- 
нем дриасе (Pirrus, Rõuk, 1979) сразу же после освобождения этого района из-под льда, примерно 12600-12200 лет назад (Серебрянный, Раукас, 1966).

Озерно-ледниковые глины покрыты серыми и темно-серыми алевритами, иногда имеющими зеленоватый оттенок, мощность которых в оз. Пиккъярв достигает 3 м. В алевритах на определенных уровнях прослеживаются тонкие слойки органического вещества и зеленых мхов, которые в наиболее глубоких частях озер оравнительно хорошо минерализированы. Алевриты значительно выравнивают донный рельеф озер, покрывая небольшие бугры и углубления. Они образовались в аллерёде и в позднем дриасе в самостоятельных озерных бассейнах в условиях интенсивной эрозин, о чем свидетельствует высокое содержание в них $\mathrm{Mg}, \mathrm{Na}$ и $\mathrm{K}$. Низкие значения содержаний $\mathrm{C}, \mathrm{H}$ и $\mathrm{N}$ и их соотношения указывают на умеренное накопление органического вещества (рис. 4).

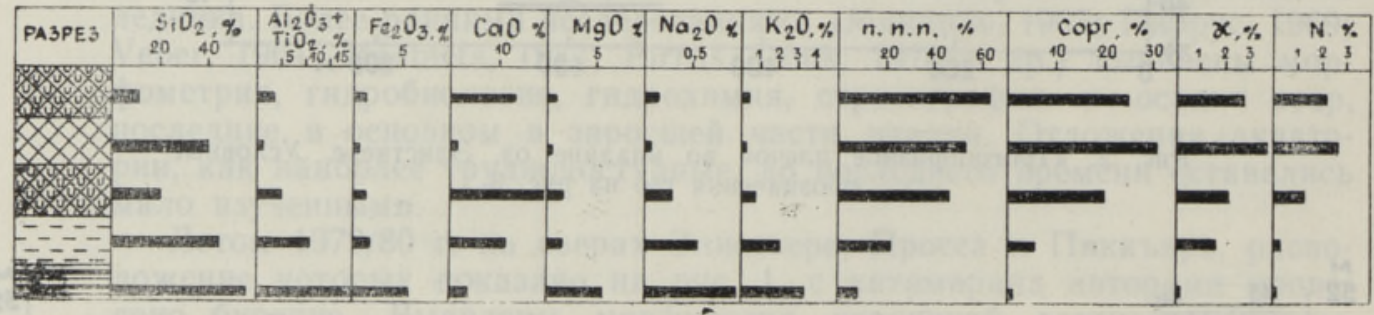

Рнс. 4. Сводный химический и элементный состав по усредненному разрезу. Условные обозначения см. на рис. 3 .

Граница между алевритами и сапропелями расплывчата и в природе трудно уловима, так как нижняя часть сапропелевой толщи содержит озерную известь или алеврит, что придает отложению сероватый оттенок. Снизу вверх выделяются следующие разновидности сапропеля: серовато-коричневый известковистый (в озерах Элиствере и Просса) местами алевритистый сапропель (оз. Пиккъярв), темнокоричневый тонкодетритовый чистый сапропель и серовато-коричневый грубодетритовый сапропель с линзами и прослойками озерной извести, сменяющийся в береговой полосе сапропелевыми известковистыми отложениями (рис. 3). Хотя мощность отдельных разновидностей сапропеля изменчива, общая мощность сапропелевой толщи в конкретных водоемах сравнительно выдержана и составляет в оз. Элиствере в среднем 2,9 м, в оз. Пиккъярв $-3,8 м$ и в оз. Просса $-3,5 м$. Рассчитанные ориентировочные запасы сапропеля в оз. Элиствере составляют 5 млн. $\mu^{3}$, в оз. Пиккъярв -2 млн. $\mu^{3}$ и в оз. Просса 1 млн. $\mu^{3}$. По данным спорово-пыльцевого анализа можно предполагать, что известковистые и алевритистые сапропели образовались в пребореале и бореале, чистые сапропели - в основном во время климатического оптимума голоцена, а верхние известковистые разновидности - во время суббореала и субатлантики (Мянниль, 1967; Пиррус, 1969; Pirrus, Rõuk, 1979).

В химическом составе сапропеля потеря при прокаливании. как приближенный показатель содержания органического вещества, явно преобладает над всеми другими компонентами, составляя в зависимости от характера сапропеля 47-69\% (рис. 4). В терригенных отложениях этот показатель снижается до $7-9 \%$.

Содержание кремнезема в сапропелях колеблется довольно значительно - от 11 до 40\%, уменьшаясь в карбонатных и увеличиваясь в чистых разновидностях. В терригенных озерных и озерно-леднико- 
Вых отложениях содержание $\mathrm{SiO}_{2}$ достигает $56 \%$. По данным рентгеноेструктурного анализа основными носителями кремнезема являются кварц, полевые шпаты и глинистые минералы.

Содержание глинозема хорошо коррелируется с количеством глинистой составляющей: чистые и известковистые сапропели содержат глинозема - $1-5$, алевриты - 11 и ленточные глины - до $20 \%$. Алюмокремниевый модуль $\left(\mathrm{Al}_{2} \mathrm{O}_{3} / \mathrm{SiO}_{2}\right)$ увеличивается от чистых сапропелей $(0,20)$ к ленточным глинам $(0,36)$.

К окислам, постоянно присутствующим в донных отложениях изучен ных озер, относится $\mathrm{Fe}_{2} \mathrm{O}_{3}$. Содержание железа в чистых сапропелях менее 1 , в известковистых $1,5-2,5 \%$, в алевритах 3,5 и в ленточных глинах до $6,6 \%$. Такое распределение обусловлено тем, что основными носителями железа являются минералы тяжелой подфракции (ильменит, магнетит, пирит, биотит и др.), а также глинистые минералы в основном гидрослюды. Кроме того, сравнительно небольшое количество железа говорит о том, что в изученных озерах не происходит прямой садки железистых минералов.

Содержание $\mathrm{CaO}$ и $\mathrm{MgO}$ в сапропелях колеблется в больших пределах — от 1,60 и 0,64 до 20 и 1,4\% соответственно (рис. 4). При этом в сапропелях прослеживаются два максимума карбонатонакопления. Первый, раннеголоценовый максимум, связан с интенсивным выщелачиванием почв на водосборной площади, что обусловило обогашение озерных вод ионами $\mathrm{HCO}_{3}^{\prime}$. Для второго, позднеголоценового максимума карбонатонакопления, характерно прежде всего обмеление и эвтрофирование озер. Содержание $\mathrm{CaO}$ в алевритах снижается до $11-12 \%$, а в ленточных глинах до $3-4 \%$. По данным рентгеноструктурного анализа в сапропелях присутствует только кальцит, в верхней части алеврита - совместно кальцит и доломит, в нижней части алеврита и в ленточных глинах - в основном доломит. Это хорошо прослеживается и по соотношению $\mathrm{CaO} / \mathrm{MgO}$, которое в известковистых сапропелях составляет $12-15$, в алевритах $7-8$, в чистых сапропелях $2-3$ и в ленточных глинах $1-1,5$. При этом в трех последних типах отложений наблюдается четко выраженная обратная связь между содержанием $\mathrm{SiO}_{2}$ и $\mathrm{CaO}$.

Хотя содержание $\mathrm{K}_{2} \mathrm{O}$ и $\mathrm{Na}_{2} \mathrm{O}$ значительно уступает содержанию других элементов, его информативность довольно большая. Выявлено, что эти элементы в основном связаны с минеральными составляющими (Mackereth, 1965), отражая интенсивность эрозии на водосборной площади. Как видно из рис. 4, наивысшие значения $\mathrm{K}_{2} \mathrm{O}, \mathrm{Na}_{2} \mathrm{O}$ и $\mathrm{MgO}$ связаны с терригенными отложениями позднеледниковья, когда интенсивность эрозии свежих малолитифицированных гляцигенных отложений была самой значительной. Минимальные значения этих элементов связаны с чистыми тонкодетритовыми сапропелями в стабильных почвах. Второе, хотя и небольшое увеличение содержания названных элементов в верхних частях разрезов отражает повышение эрозии почв, вызванной хозяйственной деятельностью человека - прежде всего вырубкой лесов, увеличением пахотных земель и применением удобрений. На палинологических диаграммах это выражается в уменьшении общего количества пыльцы древесных пород и в одновременном увеличении содержания пыльцы травянистых растений.

М инеральный состав донных отложений озер изучен рентгенодифрактометрическим методом по 33 пробам в Институте геологии под руководством Э. Пирруса. Чистые сапропели весьма однотипные, содержат в основном рентгеноаморфное вещество, кварц и незначительно кальцит. На дифрактопрамме известковистых сапропелей вырисовываются четкие пики кальцита и кварца, реже доломита и пирита. Содержание глинистых минералов в сапропелях ниже чувствительности 


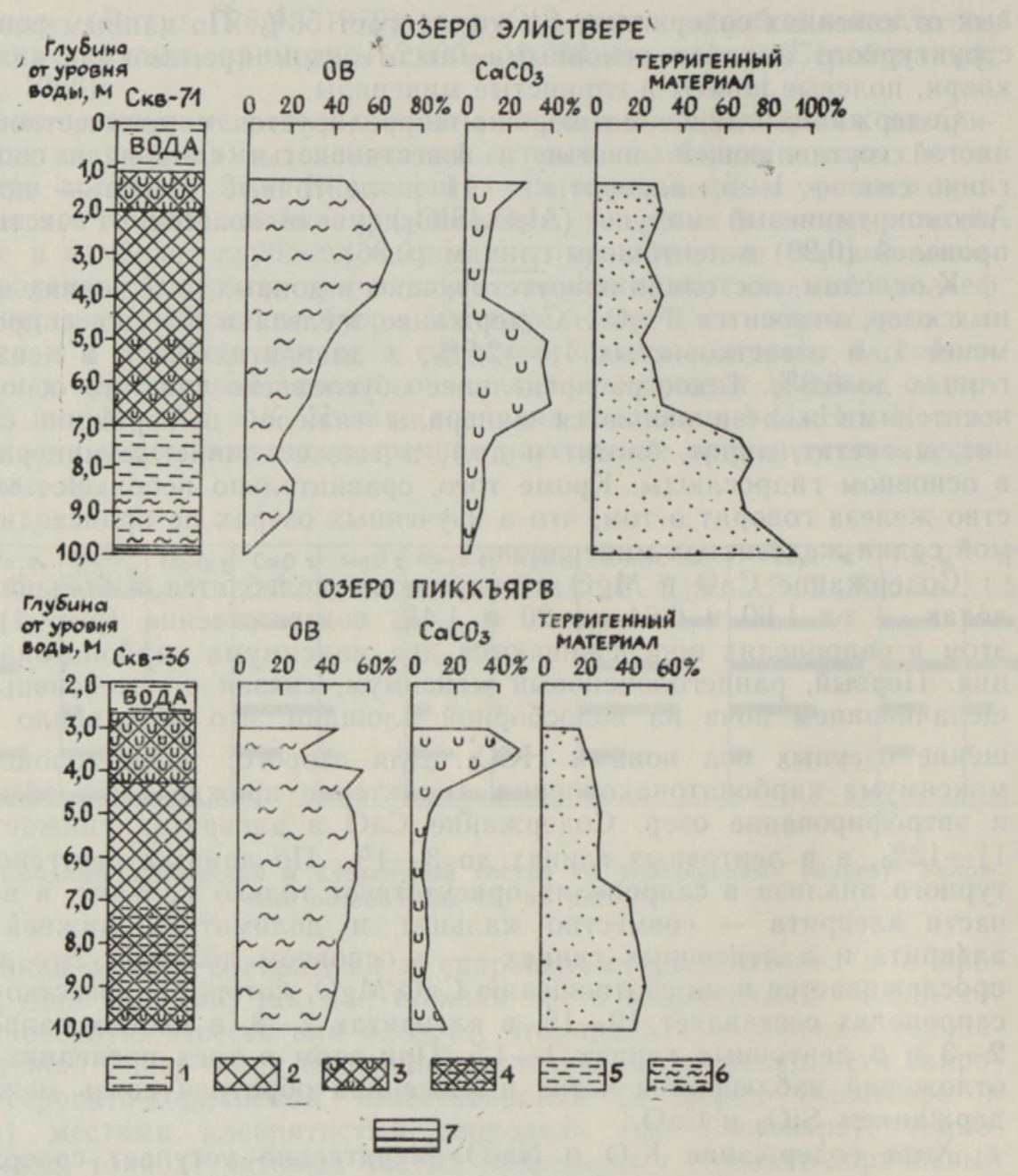

Рис. 5. Состав донных отложеннй. 1 - вода, 2 - сапропель, 3 - известковистый сапропель, 4 - алевритистый сапропель, 5 алеврит, 6 - алеврит с органическим веществом, $7-$ ленточная глина.

метода определения. В алевритах присутствуют гидрослюды, каолинит и хлорит. В составе примесных минералов идентифицированы кальцит, кварц, полевые шпаты, доломит и почти во всех образцах - пирит. Последний установлен и в ленточных глинах и в двух пробах морен. По своему генезису пирит, видимо, аллотигенный, так как он довольно часто встречается и в коренных породах (Юргенсон, 1970). Однако не исключен и аутигенный характер минералообразования пирита путем разложения органического вещества без доступа свободного кислорода в более глубоких участках озер.

Наиболее важными элементами озерных отложений, определяющими их состав и область применения, являются органический, карбонатный и терригенный материалы (рис. 5). Содержание органического вещества колеблется в довольно больших пределах - от нуля в ленточных глинах до $67 \%$ в тонкодетритовых сапропелях, примерно в средней части разрезов. Такое распределение органического вещества по вертикальному разрезу характерно и для озерных отложений других стран, 
что отражает глоб̈альное потепление климата в среднем голоцене, cóпровождающееся увеличением биопродукции и интенсивности осадконакопления (Mackereth, 1965).

Накопление карбонатов имеет противоположный характер. В опорных разрезах, заложенных в наиболее глубоких участках озер, наибольшее количество карбонатов отмечено в нижнем и верхнем голоцене, наименьшее - в среднем голоцене. Распределение карбонатов и органического вещества в мелководной фации иное. Здесь местами карбонатонакопление, начавшееся в пребореале, продолжалось и во время климатического оптимума голоцена (Мянниль, 1967).

Накопление терригенного материала превалировало в позднеледниковье, резко уменьшилось на транице голоцена и достигло минимума во время максимального накопления органического вещества (рис. 5).

Итак, в настоящее время в небольших, неглубоких, высокой степени трофности озерах Вооремаа происходит одновременное накопление карбонатных и органических веществ, обусловленное особенностями их питания и гидрохимического режима. Отличительные черты осадконакопления в отдельных озерах обусловлены лимнологическими условиями внутри озер. В голоцене наиболее интенсивное сапропеленакопление происходило в озерах Элиствере и Пиккъярв, карбонатонакопление - в оз. Просса.

\section{ЛИТЕРАТУРА}

Каяк К. Ф. К геологии Саадъярвского друмлинового поля. - Литология и стра. тиграфия четвертичных отложений Эстонии. Таллин, 1965, 23-28.

М янни и ь Р. П. Некоторые черты осадконакопления в поздне- и послеледниковых озерах Эстонии. - В кн.: Исторня озер северо-запада. Л., 1967, 300-305.

О р в и к К. К. Геологическое строение друмлинов Эстонии. - В кн.: Мат. Всесоюзн. совещ. по изуч. четвертичного периода, 2. М., 1961, 64-72.

П и р р у Р. Стратиграфнческое расчленение позднеледннковых отложений Южной Эстонии по данным спорово-пыльцевого анализа. - Изв. АН ЭССР. Хим. Геол., 1969, 18, 181-190.

Р а ука с А., Р яхни Э., М йдел А. Краевые ледниковые образования Северной Эстонии. Таллин, 1971.

Р ы у А.-М. О текстурах морен в друмлинах средней Эстонии. - Изв. АН ЭССР. Хим. Геол., 1974, 23, 149-160.

С еребрянный Л. Р., Р аука с А. В. Трансбалтийские корреляции краевых ледниковых образований позднего плейстоцена. - В кн.: Верхний плейстоцен, Стратиграфия и абсолютная геохронология. М., 1966, $12-27$.

Ю ргенсон Э. Минеральный состав. - В кн.: Силур Эстонии. Таллин, 1970, 78 -92. Eesti järved. Tallinn, 1968.

Mackereth, F. J. H. Chemical investigation of lake sediments and their interpretation. - Proc. R. Soc. B, 1965, 295-309.

Mäemets, A. Eesti NSV järved ja nende kaitse. Tallinn, 1977.

Pirrus, R., Rõuk, A.-M. Uusi andmeid Soitsjärve nõo geoloogiast. - Rmt.: Eesti NSV saarkōrgustike ja järvenõgude kujunemine. Tallinn, 1979, 118-144.

Veber, K. Sapropeel Eesti NSV järvedes. - Rmt.: Eesti NSV sood. EMMTUI teaduslike tööde kogumik, 4. Saku, 1964, 155-173.

Институт геологии

Академии наук Эстонской ССР
Поступила в редакцию $6 / \mathrm{X} 1981$

Тартуский государственный университет 


\section{SETETE KUHJUMISE ISEÄRASUSED ELISTVERE, PROSSA JA PIKKJÄRVES}

Artiklis on esitatud andmeid Elistvere, Prossa ja Pikkjärve setete lasuvuse, koostise ja kuhjumise iseärasuste kohta.

\section{Leili SAARSE, J. KARSON}

\section{SEDIMENTATIONAL PECULIARITIES OF THE LAKES ELISTVERE, PROSSA AND PIKKJÄRV}

The Lakes Elistvere, Prossa and Pikkjärv are situated in the eastern part of Estonia, in deep depressions between the drumlins of the Saadjärv drumlin field. The abovementioned lake basins have been formed as a result of the combinations of the erosional and accumulative action of the glacier and meltwaters.

The lake sediments consist of varying layers of gyttja (iine detritus, silty and calcareous gyttja) that overlie silt, varved clay and till. The limnoglacial and lacustrine minerogenic sediments originate from the Dryas. Geological and palynological data have revealed that the formation of gyttja with its present thickness of about $2.9 \mathrm{~m}$ in the Elistvere, $3.5 \mathrm{~m}$ in the Prossa and $3.8 \mathrm{~m}$ in the Pikkjärv Lake started in the Pre-Boreal climatic period and has been lasting up to the present time. In the deep-water conditions the deposition of gyttja and calcareous gyttja proceeded throughout the whole Holocene, whereas in the shallow waters lacustrine lime was deposited.

The data of chemical analyses prove that in the investigated lakes the prevailing sediment is nowadays calcareous gyttja. $\mathrm{K}_{2} \mathrm{O}, \mathrm{Na}_{2} \mathrm{O}$ and $\mathrm{MgO}$ contents are increasing constantly in the uppermost part of the sequence. The observable increase in the herbaceous plant pollen and the simultaneous decrease in the tree pollen is a result of human action. 